\title{
Task-Dependent Effects of Intra-amygdala Morphine Injections: Attenuation by Intra-amygdala Glucose Injections
}

\author{
Michael E. Ragozzino and Paul E. Gold \\ Department of Psychology, University of Virginia, Charlottesville, Virginia 22903
}

Intraseptal injections of morphine impair learning and memory in rats, and these impairments are reversed by intraseptal injections of glucose. With evidence that injections of morphine into the amygdala also impair memory for some tasks, the present experiment determined whether (1) intraamygdala morphine injections impair performance in inhibitory avoidance and spontaneous alternation tasks, and (2) intra-amygdala glucose injections attenuate the effects of intra-amygdala morphine injections. Rats receiving bilateral injections of morphine $(4.0 \mathrm{nmol})$ into the amygdala, $30 \mathrm{~min}$ prior to training in inhibitory avoidance, had retention latencies significantly lower than those of unoperated and CSF controls when tested $24 \mathrm{hr}$ later. Bilateral morphine injections (4.0 or $\mathbf{8 . 0} \mathrm{nmol}$ ) $\mathbf{3 0}$ min prior to testing in a spontaneous alternation task did not alter performance. The morphineinduced impairment observed in inhibitory avoidance was not due to diffusion up the cannulas, altered sensitivity to shock, or seizure activity. A glucose dose of $16.67 \mathrm{nmol}$, but not $8.33 \mathrm{nmol}$, injected into the amygdala attenuated the morphine-induced deficit in inhibitory avoidance. Rats receiving CSF into the amygdala exhibited decreased retention latencies in inhibitory avoidance compared to those of unoperated controls. This decrease was not attenuated by glucose at doses of $\mathbf{8 . 3 3}$ and $\mathbf{1 6 . 6 7} \mathrm{nmol}$. Therefore, these findings suggest that the amygdala is another brain region in which glucose affects brain functions, possibly by interacting with the opioid system and/or other neurotransmitter systems.

[Key words: memory, glucose, morphine, amygdala, inhibitory avoidance, spontaneous alternation]

Numerous experiments indicate that glucose modifies learning and memory (for reviews, see Gold, 1991, 1994; White, 1991). Glucose administration enhances memory in rodents, hcalthy elderly subjects, and Alzheimer's patients (Gold, 1986; Messier and White, 1987; Messier and Destrade, 1988; Hall et al., 1989; Manning et al., 1990, 1992, 1993; Packard and White, 1990; Fernandez, 1992). Furthermore, glucose injections into the lateral ventricles enhance memory, suggesting that glucose may have direct central actions on mnemonic processes (Lee et al., 1988).

Received Mar. 14, 1994; May 23, 1994; May 26, 1994.

This work was supported by research grants from NSF (BNS-9012239), NIA (AG 07648), NIH (NS-32914), and ONR (NOOO1489-J-1216). M.E.R. was a predoctoral trainee on an NIMH training grant (5-T32-MH18411).

Correspondence should be addressed to Paul E. Gold, Department of Psychology, Gilmer Hall, University of Virginia, Charlottesville, VA 22903.

Copyright @ 1994 Society for Neuroscience $0270-6474 / 94 / 147478-08 \$ 05.00 / 0$
To begin a pharmacological analysis of glucose effects on mnemonic processing, a series of experiments, using systemic injections, examined glucose interactions with drugs that affect learning and memory. One set of findings indicate that glucose attenuates memory impairments induced by muscarinic and nicotinic cholinergic antagonists (Stone et al., 1988a, 1991; Messier et al., 1990; Ragozzino and Gold, 1991). Glucose also attenuates the effects of the opioid agonist, morphine, on memory and other measures (Stone et al., 1990, 1991; ArankowskySandoval and Gold, unpublished observations). Thus, when injected systemically, glucose interacts with drugs directed at both the cholinergic and opioid systems.

More recently, we began to examine the effects of direct brain injections with glucose and other drug treatments on learning and memory. Findings from numerous experiments indicate that lesions or direct pharmacological manipulations of the septal area affect learning and memory (Winocur and Mills, 1969; Bostock ct al., 1988; Chrobak ct al., 1989; Givens and Olton, 1990; Mizumori et al., 1990; Decker et al., 1992; Izquierdo et al., 1992). The septal area may be one brain site in which glucose has modulatory effects to influence learning and memory processes. We found that intraseptal injections of morphine impair performance in spontaneous alternation and inhibitory avoidance tasks (Ragozzino et al., 1992). Furthermore, systemic and intraseptal injections of glucose attenuate impairments resulting from intraseptal morphine injections. These findings suggest that the septal area may be one brain region susceptible to glucose modulation.

Another brain area of interest in studying glucose modulation of mnemonic processing is the amygdala. Similar to the medial septum, manipulations of the amygdala, that is, lesions, chemical or electrical stimulation, produce changes in learning and memory (Gold et al., 1975; Gallagher and Kapp, 1978; Kesner and Andrus, 1982; Hitchcock and Davis, 1987; Brioni et al., 1989; Izquierdo et al., 1992). The amygdala binds high levels of opioid ligands (Zamir et al., 1985). Behavioral and pharmacological studies indicate that glucose interacts with opioids (Brase et al., 1987; Stone et al., 1990, 1991). Because glucose reduces the mnemonic deficits induced by intraseptal morphine treatment (Ragozzino et al., 1992), glucose may interact with opioids in other brain areas to alter mnemonic functioning.

The present experiment determined whether intra-amygdala morphine injections impaired spontaneous alternation and inhibitory avoidance performance, as observed previously with intraseptal morphine injections. The experiment also determined whether intra-amygdala glucose administration attenuated impairments induced by intra-amygdala morphine injections. The findings indicate that intra-amygdala injections of morphine impair performance in an inhibitory avoidance but 
not a spontaneous alternation task. Furthermore, intraamygdala injections of glucose attenuate the inhibitory avoidance deficit produced by intraamygdala morphine injections.

\section{Materials and Methods}

\section{Subjects}

Male Sprague-Dawley rats (Charles River Breeders, Wilmington, MA), weighing between 300 and $400 \mathrm{gm}$ at the time of surgery, served as subjects. Rats were housed individually with food and water available ad libitum. They were maintained on a $12 \mathrm{hr}$ light/dark cycle (lights on $0700 \mathrm{hr}$ )

\section{Surgery}

Rats received atropine sulfate $(0.2 \mathrm{cc}$ of a $540 \mu \mathrm{g} / \mathrm{cc}$ solution, i.p.) 20 min prior to being anesthetized with sodium pentobarbital $(65 \mathrm{mg} / \mathrm{kg}$, i.p.). After being anesthetized, stainless steel guide cannulas (22 gauge; Plastics One, Inc., Roanoke, VA) aimed dorsal to the central nucleus of the amygdala were implanted bilaterally. The stereotaxic coordinates were $0.4 \mathrm{~mm}$ posterior from bregma, \pm 4.5 latcral, and 7.0 ventral from dura. The nose bar was set at $5.0 \mathrm{~mm}$ above the interaural line according to the atlas of Pellegrino et al. (1979).

In another sel of rats, cannulas were implanted in the striata, using the stereotaxic coordinates as above except the cannulas were lowered $4.5 \mathrm{~mm}$ below dura.

\section{Intracranial injections}

Bilateral injections into the amygdala or striatum were administered through an inner cannula that extended $1.0 \mathrm{~mm}$ below the guide cannula. The 28 gauge inner cannula was attached by a polyethylene tube to a $25 \mu \mathrm{l}$ Hamilton syringe. The syringe was driven by an infusion pump with solutions administered in a volume of $0.5 \mu \mathrm{l}$ at a rate of $0.5 \mu \mathrm{l} /$ min. Prior to removal, the injection cannula was left in place for an additional minute to allow diffusion. All drugs were mixed in artificial cerebrospinal fluid (CSF) that contained $3.33 \mathrm{nmol}$ of glucose and $\mathrm{pH}$ to 7.4. The doses of morphine and glucose, specified below, were chosen because previous experiments demonstrated effects in memory tests at these doses (Ragozzino et al., 1992).

\section{Behavioral procedures}

Inhibitory avoidance. One week after surgery, rats were trained in an inhibitory avoidance task between 0800 and $1200 \mathrm{hr}$. Cannulated rats received injections $30 \mathrm{~min}$ prior to training, the same as in previous experiments with systemic and intracranial injections of morphine (Stone et al., 1991; Ragozzino et al., 1992). Rats implanted with cannulas in the amygdala were assigned to one of the following groups: (1) CSF ( $N$ $=13),(2)$ morphine sulfate $(4.0 \mathrm{nmol} ; N=16),(3)$ morphine sulfate $(4.0 \mathrm{nmol})$ and glucose $(8.33 \mathrm{nmol} ; N=10),(4)$ morphine sulfate $(4.0$ nmol) and glucose $(16.67 \mathrm{nmol} ; N=13)$, $(5)$ glucose $(8.33 \mathrm{nmol} ; N=$ $8)$, (6) glucose (16.67 nmol; $N=8$ ). Combined morphine and glucose treatment was administered in a single "cocktail" injection. Rats implanted with cannulas in the striata were assigned to one of the following groups: (1) $\operatorname{CSF}(N=7)$, (2) morphine sulfate (4.0 nmol; $N=6$ ). Another group of rats served as unoperated controls $(N=12)$. Inhibitory avoidance training was conducted in a trough-shaped alley $(90.0 \mathrm{~cm}$ long, 15 $\mathrm{cm}$ high, $20 \mathrm{~cm}$ ceiling width, and $5.5 \mathrm{~cm}$ floor width) divided into two compartments by a sliding door. On the training trial, each rat was placed into a well-lit compartment ( $30 \mathrm{~cm}$ long). After $20 \mathrm{sec}$ the door was opened and the rat was allowed to enter a dark shock compartment. Following entry into the dark compartment, the door was closed behind the rat and a footshock $(2.0 \mathrm{~mA}, 1 \mathrm{sec})$ was delivered by a shock apparatus ( $900 \mathrm{k} \Omega$ resistor; Lafayette Instruments) through metal plates that comprised the floor and walls of the trough. Retention was tested $24 \mathrm{hr}$ later by placing the rat in the start compartment and measuring the latency to cross into the dark compartment (600 sec maximum).

Separate groups of rats with amygdala cannulas and unoperated controls were used to assess whether morphine injections altered footshock sensitivity. This was determined by measuring flinch-jump thresholds using an ascending series of shock intensities. Cannulated rats received one of the following treatments, (1) CSF $(N=4)$, (2) morphine sulfate $(4.0 \mathrm{nmol} ; N=4)$, (3) glucose (16.6 nmol; $N=3)$, (4) morphine sulfate $(4.0 \mathrm{nmol})$ and glucose $(16.6 \mathrm{nmol} ; N=3), 30 \mathrm{~min}$ prior to testing. Shock intensity began at $30 \mu \mathrm{A}$ ( 1 sec duration) and was increased by
$30 \mu \mathrm{A}$ every $30 \mathrm{sec}$. The lowest shock intensity at which a rat exhibited a behavioral response was considered the flinch threshold. The lowest shock intensity at which a rat's paws left the floor was recorded as the jump thrcshold.

Spontaneous alternation. Three to five days following inhibitory avoidance testing, the same rats were tested in a $Y$-maze for spontaneous alternation behavior. Testing occurred between 0800 and $1200 \mathrm{hr}$. Rats were assigned to a different group so that no rat received the same treatment in the spontaneous alternation task as on the inhibitory avoidance task. All cannulated rats were injected 30 min prior to testing. The treatment groups were the same as in inhibitory avoidance with the addition of a group that received a higher dose of morphine $(8.0 \mathrm{nmol})$ injected into the amygdala. The size of the groups ranged from 5 to 10 .

The testing procedure was based on that of Sarter et al. (1988). The $\mathrm{Y}$-maze consisted of three trough-shaped arms radiating from a central triangle. The length of each arm was $60 \mathrm{~cm}$, the height of the maze was $17.5 \mathrm{~cm}$, the width of the floor was $3.5 \mathrm{~cm}$, and the width of the ceiling was $14 \mathrm{~cm}$. The central triangular area was $4 \mathrm{~cm}$ along its longest axis. The ceiling was covered with translucent black Plexiglas. The rats were placed in one arm and allowed to traverse the maze freely for $8 \mathrm{~min}$ while the number and sequence of entries were recorded. An alternation was defined as the consecutive entry into all three arms on overlapping triplet sets. Using this procedure, possible alternation sequences are equal to the number of arm entries minus 2 , and the percentage of alternation behavior is equal to the ratio of (actual alternations/possible alternations) $\times 100$.

Electroencephalographic recordings. To determine whether intraamygdala morphine injections produced seizures or other abnormal electroencephalographic activity, three rats were implanted with amygdala and cortical electrodes. For intra-amygdala recordings, stainless steel wire was soldered to each guide cannula $(11 \mathrm{~mm})$. Guide cannulas were insulated except at the tip $(1 \mathrm{~mm})$, thus being used for both recording and injections. The guide cannulas were implanted bilaterally at the following coordinates: $-0.4 \mathrm{AP}, \pm 4.5 \mathrm{ML}$, and 7.0 ventral from dura. The nose bar was set at $5.0 \mathrm{~mm}$. Cortical recordings were obtained from small screws, one positioned rostral to bregma $(2.0 \mathrm{~mm}$ AP from bregma and $-3.0 \mathrm{~mm} \mathrm{ML})$ and the other caudal to lambda $(-1.0$ from lambda and 3.0 ML). One to two weeks following surgery, each rat was habituated to the EEG procedure for $2 \mathrm{~d}$ in a recording room. This involved attaching a recording cable to a connector strip while each animal remained in its home cage for $3 \mathrm{hr}$. All habituation and recording procedures were carried out between 0800 and $1200 \mathrm{hr}$. Baseline EEG recordings were made for $30 \mathrm{~min}$. Continuing EEG recordings, rats then received intra-amygdala injections of morphine or CSF, using the same procedure as above, with recordings assessed up to $150 \mathrm{~min}$ after injections.

\section{Histology}

After the completion of testing, rats received an overdose of sodium pentobarbital followed by a $0.5 \mu 1$ injection of ink into each cannula. Intracardial perfusions were performed with $0.9 \%$ saline followed by a $10 \%$ formalin solution. Brains were removed and placed in a $30 \%$ sucrose/formalin solution.

In preparation for sectioning, brains were frozen at $-20^{\circ} \mathrm{C}$ and mounted on a Reichert-Jung cryostat. Forty-micrometer sections were taken beginning at the anterior amygdala, mounted onto slides, dried, and stained with cresyl violet. Figure 1 illustrates the location of injection sites and diffusion of ink in the amygdala and striatum of rats considered to have correct placements. Behavioral scores for rats with cannulas intended for the amygdala or striatum but not found in these areas, respectively, were excluded from the data analyses. In the amygdala, cannulas were aimed for the central nucleus because of the high density of opioid receptors (Zamir et al., 1985); however, data from rats with cannulas found in other amygdala nuclei (i.e., lateral, basolateral, and medial nuclei but not the cortical nucleus or anterior amygdala area) were included in the analyses. The data from these rats were included because ink injections with cannulas located in the central nuclei indicated that the ink spread to these other amygdala nuclei.

\section{Statistical analysis}

Inhibitory avoidance results were analyzed with two-tailed Mann-Whitney $U$ tests. The percentage alternation scores and flinch-jump thresholds were analyzed by independent two-tailed $t$ tests. 
Figure 1. Location of the injection cannula tips and diffusion of ink in the amygdala and striatum for all rats included in behavioral analyses. Rat brain sections were taken from the stereotaxic atlas of Pellegrino et al. (1979).

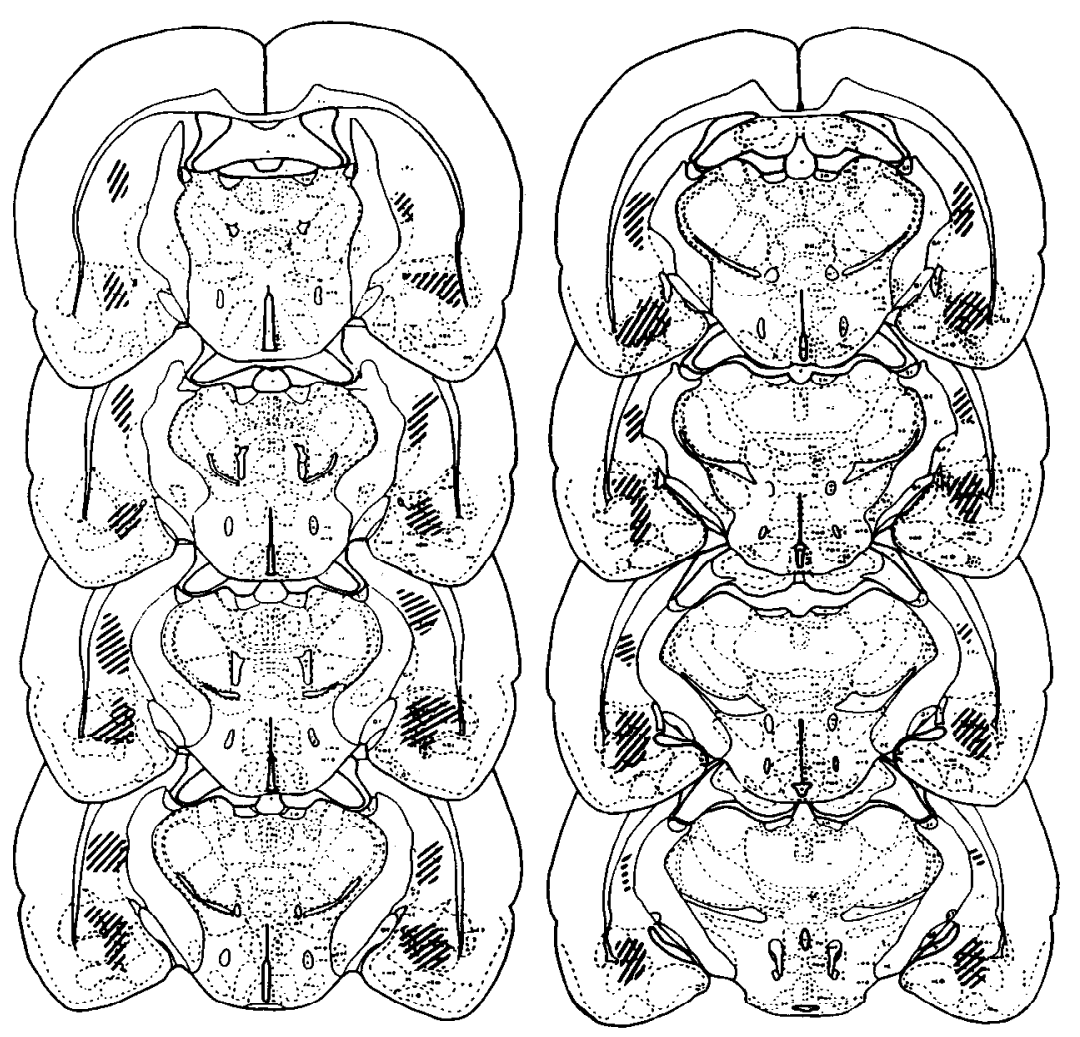

\section{Results}

\section{Inhibitory avoidance}

Intraamygdala injections of morphine impaired inhibitory avoidance learning. This impairment was attenuated by coad-

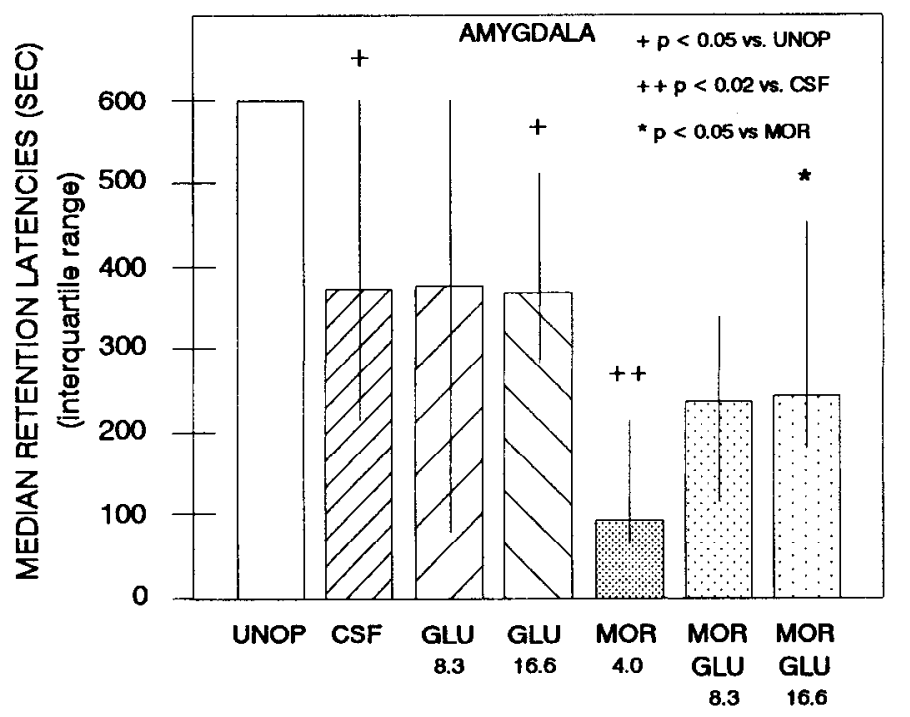

TREATMENT (NMOL/SIDE)

Figure 2. Intraamygdala glucose injections attenuate inhibitory avoidance deficits induced by morphine injections into the amygdala. Bilateral morphine $(4.0 \mathrm{nmol})$ injections into the amygdala, prior to training, significantly reduced latencies. Intra-amygdala glucose injections alone ( 8.33 and $16.67 \mathrm{nmol}$ ), prior to training, did not modify latencies, but when glucose ( $16.67 \mathrm{nmol}$ ) was coadministered with morphine, latencies were significantly greater than those after morphine treatment alonc. Cannulated controls had significantly lower latencies than those of unoperated controls. ministration of glucose. As shown in Figure 2, rats that received morphine injections into the amygdala $30 \mathrm{~min}$ prior to training had latencies significantly lower than those of unoperated $[U(12,16)=13, p<0.0001]$ and CSF controls $[U(13,16)=48$, $p<0.02]$ when tested $24 \mathrm{hr}$ after training. At the higher glucose dose $(16.67 \mathrm{nmol})$, glucose attenuated the morphine-induced impairment. The combined treatment of morphine and glucose $(16.67 \mathrm{nmol})$ produced latencies that were significantly higher than the latencies following morphine treatment $[U(10,16)=$ $40, p<0.05$ ], and were similar to those of the CSF group $[U(10,13)=56, p>0.05]$. At the lower dose $(8.33 \mathrm{nmol})$, glucose treatment resulted in latencies intermediate to those obtained after morphine or CSF treatment. The rats coadministered morphine and glucose $(8.33 \mathrm{nmol})$ into the amygdala had scores not significantly different from those of morphine-treated rats or CSF controls $[U(13,16)=69$ and $U(13,13)=59$, respectively, $p>0.05$ ]. CSF controls had significantly lower scores than those of unoperated controls $[U(12,13)=39, p<0.05]$. Intraamygdala injections of glucose $(8.33 \mathrm{nmol})$ or glucose $(16.67 \mathrm{nmol}) \mathrm{re}-$ sulted in latencies similar to those following CSF injections. The latencies of the glucose $(8.33 \mathrm{nmol})$ group were not significantly different than those of the CSF $[U(8,13)=39, p>0.05]$ or unoperated $[U(8,12)=24, p>0.05]$ controls. Rats receiving glucose ( $16.67 \mathrm{nmol}$ ) injections had scores not significantly different from those of CSF controls $[U(8,13)=51, p>0.05]$, but were significantly lower than the scores of unoperated controls $[U(8,12)=18, p<0.02]$. Thus, at neither dose did glucose reverse the inhibitory avoidance deficit produced by cannula implantation. Moreover, the two morphine-glucose groups approached the scores of the CSF group but not the unimplanted controls. The morphine-glucose (16.67 nmol) group had latencies significantly different from those of unoperated controls $[U(10,12)=22, p<0.01]$. Similarly, rats coadministered morphine and glucose ( $8.33 \mathrm{nmol})$ had significantly lower latencies 


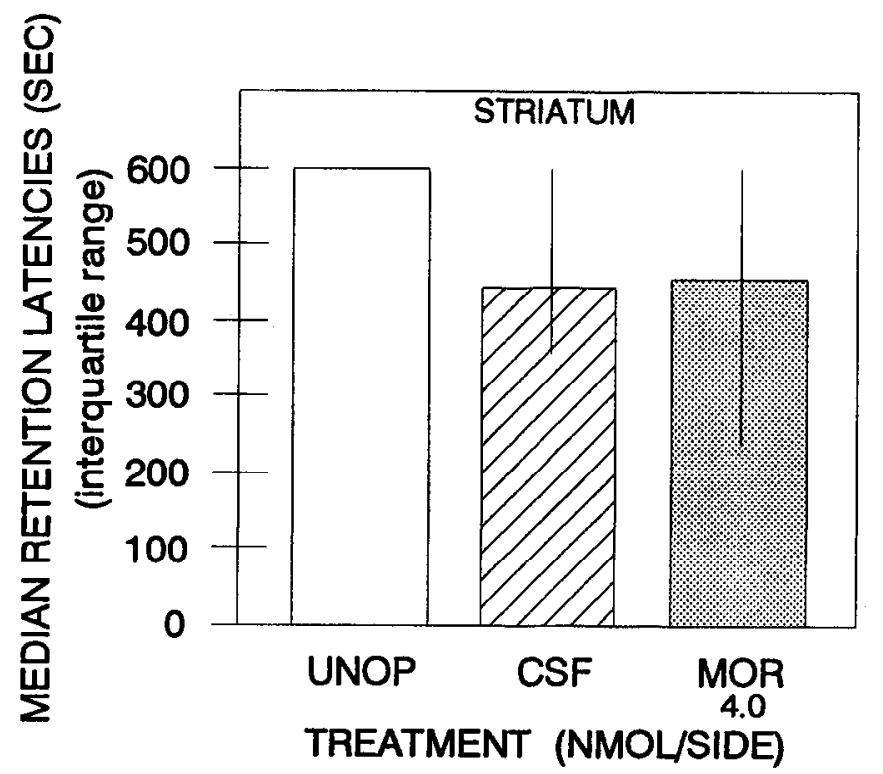

Figure 3. Bilateral morphine injections into the striatum did not impair inhibitory avoidance performance. Prior to training, morphine (4.0 $\mathrm{nmol}$ ) injected dorsal to the amygdala, in the overlying striatum did not significantly reduce latencies compared to those of unoperated and CSF controls. Similarly, CSF injections did not reduce latencies compared to those of unoperated controls.

compared to those of unoperated controls $[U(8,12)=17, p<$ $0.05]$.

Figure 3 illustrates that latencies to cross following morphine injections into the striatum were similar to those following intrastriatal CSF injections and somewhat lower than those of unoperated controls. The scores of rats receiving morphine injections were not significantly different than those of CSF $[U(6,7)$ $=20, p>0.05]$ or unoperated $[U(6,12)=24, p>0.05]$ controls. CSF controls had latencies comparable to those of unoperated controls $[U(7,12)=22, p>0.05]$.

Figure 4 illustrates that there were no differences in flinchjump thresholds between any of the groups. The flinch thresholds to footshock for unoperated (mean $=172.5 \mu \mathrm{A}, \mathrm{SEM}=$ \pm 22.5 ) and intra-amygdala $\mathrm{CSF}$ (mean $=150 \mu \mathrm{A} \pm 12.2$ ) controls did not differ from each other $[t(6)=0.88, p>0.05]$. Flinch thresholds for the groups receiving morphine (mean = $165 \pm 19.4 \mu \mathrm{A})$, morphine-glucose (mean $=150 \pm 17.3 \mu \mathrm{A})$, or glucose (mean $=160 \pm 20 \mu \mathrm{A}$ ) were comparable to those of unoperated and CSF controls $(p>0.05)$. Similar to flinch thresholds, jump thresholds were not significantly different between those of unoperated (mean $=435 \pm 35.7 \mu \mathrm{A}$ ) and CSF $($ mean $=480 \pm 53.4 \mu \mathrm{A})$ controls $[t(6)=0.70, p>0.05]$. The jump thresholds for the groups receiving morphine (mean $=$ $480 \pm 30 \mu \mathrm{A})$, morphine-glucose (mean $=460 \pm 36.1 \mu \mathrm{A})$, or glucose (mean $=500 \pm 40 \mu \mathrm{A}$ ) did not differ from those of unoperated and CSF controls $(p>0.05)$.

\section{Spontaneous alternation}

The findings shown in Figure 5 indicate that intra-amygdala morphine injections did not impair spontaneous alternation performance. Similar to previous observations (e.g., Parsons and Gold, 1992; Ragozzino et al., 1992), unoperated and CSF controls had alternation scores near $70 \%$ (means $=66.9 \pm 4.2$ and $66.7 \pm 3.0$, respectively). Rats receiving intra-amygdala morphine iniections $(4.0 \mathrm{nmol})$ had alternation scores (mean $=62.4$

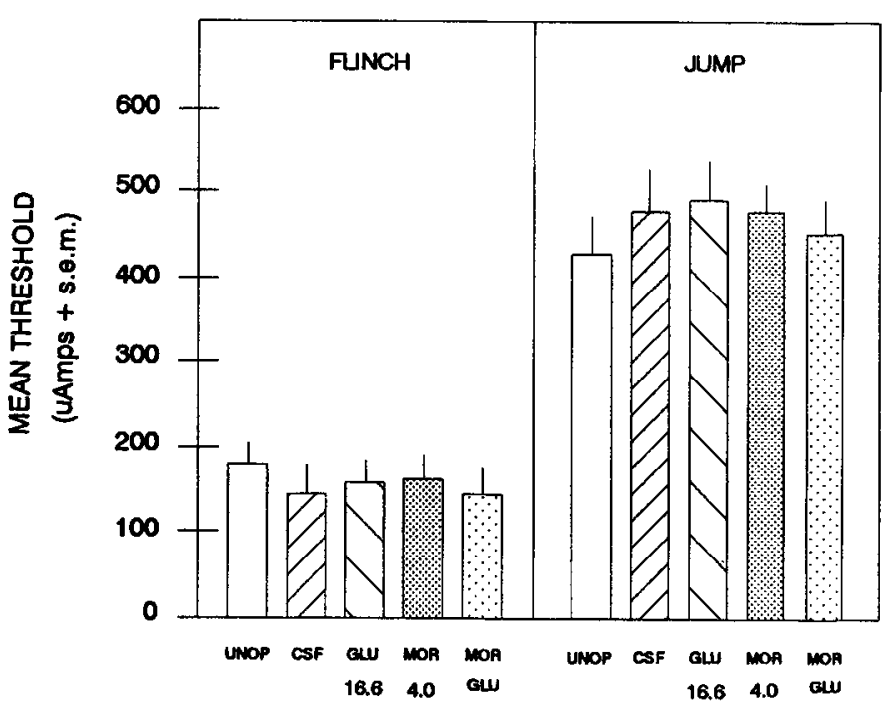

TREATMENT (NMOL/SIDE)

Figure 4. Bilateral amygdala injections of morphine, glucose, or morphine-glucose did not modify flinch-jump thresholds. Rats receiving morphine, glucose, or morphine-glucose injections into the amygdala resulted in flinch-jump thresholds not significantly different from those of unoperated and CSF controls.

$\pm 4.2)$ similar to those of unoperated and CSF controls $[t(17)$ $=0.49$ and $t(16)=0.50$, respectively, $p>0.05$ ]. As seen with the lower dose, the $8.0 \mathrm{nmol}$ dose of morphine (mean $=67.6$ \pm 4.5 ) did not modify spontaneous alternation performance compared to that of unoperated and CSF controls $[t(13)=0.10$ and $t(12)=0.12$, respectively, $p>0.05$ ]. The scores of CSF controls were not significantly different from those of unoperated controls $[t(15)=0.05, p>0.05]$.

As shown in Figure 6, morphine injections into the striatum did not impair spontaneous alternation performance. Rats re-

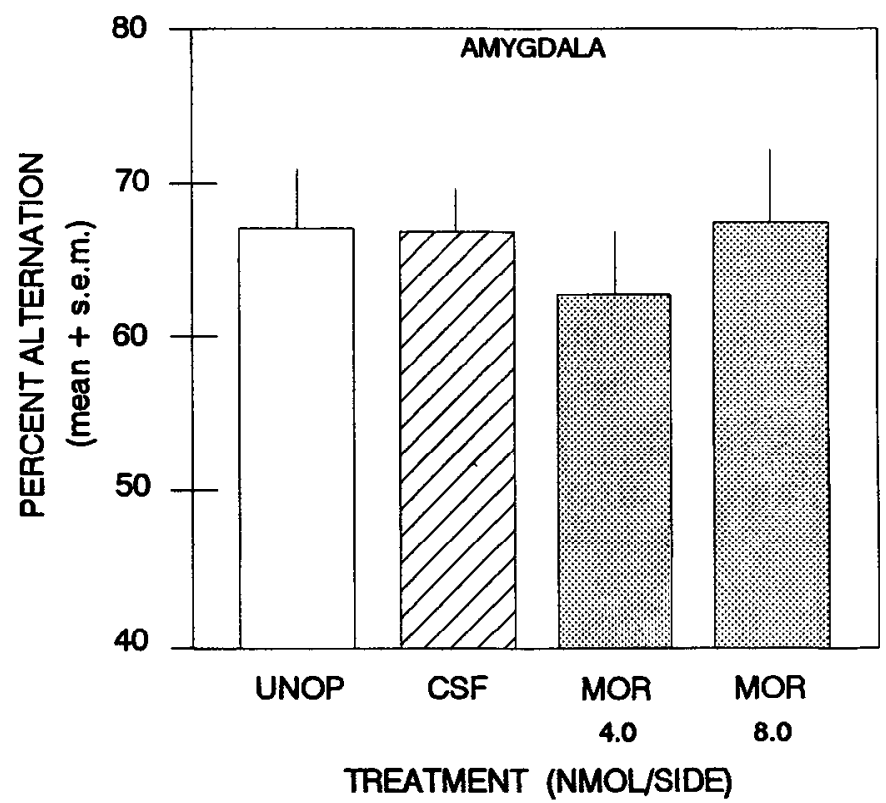

Figure 5. Intra-amygdala morphine injections did not impair spontaneous alternation performance. Bilateral morphine (4.0 and 8.0) injections into the amygdala did not significantly modify spontaneous alternation performance compared to that of unoperated and CSF controls 


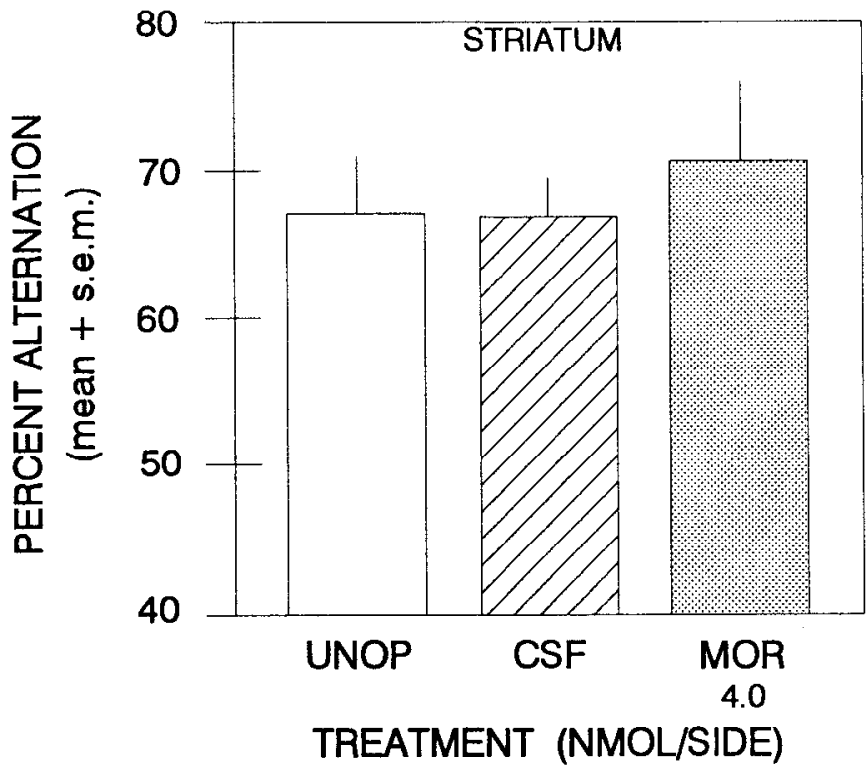

Figure 6. Bilateral morphine injections into the striatum did not impair spontaneous alternation performance. Morphine (4.0) injected dorsal to the amygdala, in the overlying striatum, did not significantly change spontaneous alternation scores compared to those of CSF and unoperated controls.

ceiving morphine injections into the striatum had alternation scores not significantly different from those of unoperated and CSF controls $[t(12)=0.67$ and $t(11)=0.54$, respectively, $p>$ $0.05]$. The alternation scores of CSF-injected controls were comparable to those of unoperated controls $[t(15)=0.27, p>0.05]$.

Similar to previous experiments (Ragozzino and Gold, 1991; Ragozzino et al., 1994; Ragozzino, Hellems, Lennartz, and Gold, unpublished observations), minor differences in the number of arm choices between the groups occurred but did not appear related to the alternation scores. Unoperated controls (mean $=$ $19.2 \pm 1.1)$ made significantly fewer arm choices than did CSF controls (mean $=24.1 \pm 1.4)[t(15)=2.78, p<0.02]$. The number of arms entered by the $4.0 \mathrm{nmol}$ morphine group (mean $=19 \pm 3.1$ ) was not significantly different from those of unoperated and CSF controls $[t(17)=0.06$ and $t(16)=1.38$, respectively, $p>0.05$ ]. The $8.0 \mathrm{nmol}$ morphine group (mean $=$ $26.5 \pm 2.6$ ) chose significantly more arms than unoperated controls $[t(13)=2.93, p<0.02]$, but not CSF controls $[t(12)=$ $0.87, p>0.05]$. Rats receiving intrastriatal morphine treatment (mean $=22.2 \pm 3.5$ ) made a similar number of arm choices as rats administered CSF into the striatum (mean $=23.6 \pm 2.1$ ).

\section{Inaccurate placements}

Several rats were excluded from the data analyses because histological examination revealed that either one or both cannulas were outside the amygdala or ink was in the ventricles. There were only one to four rats excluded from each treatment group. Therefore, it was often difficult to determine any pattern of inaccurate placements by examining a single treatment group. However, because the results were similar independent of the treatment, including morphine, the data were combined across groups.

Analysis of the inaccurate placements in the inhibitory avoidance task indicated that rats with placements in the striatum or internal capsule had latencies (median $=470$ ) that were not significantly different from those of unoperated $[U(12,20)=71$, $p>0.05]$ or CSF controls $[U(13,20)=110, p>0.05]$. The latencies of rats with ink in the ventricles (median $=326$ ) were significantly lower than those of unoperated controls $[U(12,16)$ $=39, p<0.01]$ but not CSF-treated rats $[U(13,16)=39, p>$ $0.05]$. However, rats with cannula placements that penetrated through the lateral nucleus into the juxtaposed cortical area, essentially lesioning the amygdala, had latencies (median $=99$ ) that were significantly lower than those of unoperated $[U(12,7)$ $=0.01, p<0.001]$ and CSF controls $[U(13,7)=14, p<0.05]$. These findings are consistent with substantial evidence that amygdala lesions impair avoidance learning (McGowan et al., 1972; Kemble and Davis, 1981; Dunn and Everitt, 1988; Cahill and McGaugh, 1990). Importantly, the distribution of placements for rats included in the behavioral groups was quite similar across groups. No rats were included in any treatment group for analyses of drug effects in inhibitory avoidance if their placements penetrated through the lateral amygdala to the adjacent cortex. Thus, differences in cannula placement did not contribute to the drug effects described here.

In contrast to inhibitory avoidance, rats with cannulas that were in the cortex or too ventral had spontaneous alternation scores (mean $=65.4 \pm 3.2$ ) not significantly different from those of unoperated and CSF controls $[t(11)=0.32$ and $t(10)=0.25$, respectively, $p>0.05$ ]. Combining the scores from rats with dorsal placements or ink in the ventricles revealed that their performance in the spontaneous alternation task (mean $=66.8$ \pm 4.1 ) was similar to that of unoperated and CSF controls $[t(16)$ $=0.03$ and $t(15)=0.02$, respectively, $p>0.05]$.

\section{Electroencephalographic recordings}

Analysis of the EEG records indicated that intra-amygdala injections of morphine or CSF did not result in seizure-like activity within $150 \mathrm{~min}$ after injection. Immediately following injections of morphine and CSF, there was a transient increase in amplitude and frequency lasting approximately $4 \mathrm{~min}$. However, no spiking or other irregular EEG activity was found during the rest of the recording period.

\section{Discussion}

The findings of the present experiment indicated that morphine administered into the amygdala impairs performance in an inhibitory avoidance but not spontaneous alternation task. The amnesia resulting from intra-amygdala morphine injections is consistent with previous findings that intra-amygdala injections of opioid agonists cause mnemonic deficits in shock avoidance tasks (Gallagher and Kapp, 1978; Flood et al., 1992). Because morphine injections into the overlying striatum did not impair learning of the avoidance response, the inhibitory avoidance deficit after intra-amygdala morphine injections did not appear because of diffusion up the cannulas. Rather, the inhibitory avoidance deficit seemed to result from activation of opioid receptors in the amygdala. Furthermore, intra-amygdala morphine injections did not alter the rats' sensitivity to footshock or induce seizures. The $4.0 \mathrm{nmol}$ morphine dose injected into the amygdala was lower than the morphine doses injected into the amygdala previously found to modify shock thresholds (13 $\mathrm{nmol}$ ) and induce behavioral and EEG seizures (25-200 nmol) (Rodgers, 1978; Ikonomidou-Turski et al., 1987).

Besides the impairment with intra-amygdala morphine injections, rats injected with CSF into the amygdala exhibited an inhibitory avoidance deficit compared to unoperated controls, apparently the result of tissue damage within the amygdala and 
overlying areas. Similar results have been obscrved following implantation of electrodes into the amygdala (Gold et al., 1975, 1978). Thus, the deficit may result because of cannula implantation alone but also may be due to the CSF injection. The intrastriatal controls also had latencies lower than those of unoperated controls, but these were not significantly different. Injections of glucose at 8.33 and $16.67 \mathrm{nmol}$ did not reverse the deficit observed with implanted amygdala controls. Previously, we found that systemic glucose did not reverse the effect of medial septal lesions (McGlynn, Lennartz, Gold, and Gold, unpublished observations). Furthermore, Liang and McGaugh (1983) demonstrated that lesions of the stria terminalis block the memory-enhancing effect of epinephrine. These results suggest that cannula implantation or lesioning that partially damages multiple neurochemical systems in brain areas blocks the effects of modulators, such as glucose and epinephrine. However, in amygdala cannulated rats, a specific pharmacologicalinduced deficit is amendable to glucose treatment. In contrast to the inhibitory avoidance deficits, intra-amygdala morphine injections did not impair spontaneous alternation performance. This was also the case for morphine injections into the striatum. One possibility is that higher doses of morphine injected into the amygdala would impair spontaneous alternation performance, although the seizures likely at higher doses would confound an interpretation based on direct morphine actions in the amygdala.

The lack of an effect of intra-amygdala morphine injections on spontaneous alternation performance is consistent with previous experiments demonstrating that lesions or pharmacological manipulations of the amygdala do not impair performance in tasks involving spatial processing (Aggleton et al., 1989; Kesner et al., 1990; Peinado-Manzano, 1990; Stackman and Walsh, 1992). However, there are spatial components in inhibitory avoidance, as used here, and $\mathrm{Y}$-maze discriminated avoidance tasks for which memory is susceptible to amygdala lesions, electrical stimulation, or drug manipulations (Gallagher and Kapp, 1978; McGaugh et al., 1988; Brioni et al., 1989; Introini-Collison et al., 1989; Cahill and McGaugh, 1990; Flood et al., 1992). The differential effects of intra-amygdala morphine treatment in inhibitory avoidance versus spontaneous alternation tasks may be the result of different levels of affect elicited by the tasks (Kesner and Andrus, 1982; Kesner, 1992; LeDoux, 1992). Moreover, the differences observed in the memory tasks between morphine injections into the septum and amygdala indicate that these two anatomical systems are involved in different mnemonic functions. Consistent with the idea of multiple memory systems, findings from McDonald and White (1993) suggest that the septohippocampal system is involved in processing relationships between stimuli while the amygdala processes information that has affective properties.

The present study also demonstrated that intra-amygdala glucose injections attenuate the inhibitory avoidance deficit resulting from intra-amygdala morphine injections. The morphine-glucose treatment had a higher osmolarity than the morphine treatment alone, raising the possibility that the glucose attcnuation resulted because of osmolarity changes. However, intra-amygdala injections of glucose did not attenuate inhibitory avoidance deficits induced by intra-amygdala infusions of propranolol, a $\beta$-noradrenergic antagonist (Lennartz and Gold, unpublished observations). These findings suggest that the bases of glucose effects are pharmacological rather than changes in osmolarity.
The effective dose of glucose $(16.67 \mathrm{nmol})$ was similar to the glucose dose injected into the septum that attenuated impairments of both inhibitory avoidance and spontaneous alternation performance after intraseptal morphine injections (Ragozzino et al., 1992). Thus, glucose modulation of brain function is not limited to the septal region, but also includes the amygdala. Although morphine injections into the septum and amygdala impair performance for different sets of tasks, the pharmacological bases for glucose interactions may be the same. The findings from our studies, as well as others (Izquierdo et al., 1992; Stackman and Walsh, 1992), suggest that the neurotransmitter systems responsible for learning and memory are redundantly organized but their involvement in specific tasks varies depending on the neural system being manipulated.

The attenuation of the effect of intra-amygdala morphine injections by intra-amygdala glucose treatment adds to other findings, indicating that glucose attenuates the effects of morphine on several measures (Simon and Dewey, 1981; Shook et al., 1986; Stone et al., 1990, 1992; Arankowsky-Sandoval and Gold, unpublished observations). Glucose attenuation of the behavioral effects of morphine may be due to a decrease in opioidreceptor affinity because increasing glucose concentrations decrease receptor affinities for ${ }^{3} \mathrm{H}$-naloxone and ${ }^{3} \mathrm{H}$-dihydromorphine in the brain (Brase et al., 1987). If glucose acts by decreasing opioid receptor affinity, then glucose should produce effects similar to those of an opioid antagonist. We found that systemic injections of glucose and naloxone, an opioid antagonist, produce similar effects on several behavioral measures (Stone et al., 1987, 1988a,b,; Walker et al., 1991).

Another possibility is that the effects of glucose are due to direct actions on the cholinergic system. The amygdala receives an extensive cholinergic innervation (Mesulam et al., 1983) and opioid agonists decrease the release of $\mathrm{ACh}$ in amygdala slices (Frankhuijzen et al., 1991). Under certain conditions, including pharmacological treatments, hypoxia, and aging, the availability of acetyl-CoA appears to regulate $\mathrm{ACh}$ synthesis (Gibson and Blass, 1976; Gibson and Peterson, 1981; Dolezal and Tucek, 1982; Ricny et al., 1992). Brain acetyl-CoA is principally derived from glucose, and therefore circulating glucose levels may regulate ACh levels under certain conditions (Tucek and Cheng, 1974; Tucek, 1978).

It is also possible that glucose has multiple actions or acts through another neurotransmitter system involved in learning and memory processes. For example, work by McGaugh et al. (1994) demonstrated that in addition to opioid and cholinergic systems, the GABAergic system within the amygdala modulates mnemonic processes. Thus, glucose may also interact with one or more of these neurotransmitter systems in the amygdala. Future investigations measuring neurochemical changes in the amygdala following glucose treatment may elucidate the role of this modulator on brain functions.

Overall, these findings indicate that opioid receptors in the amygdala are involved in learning of an avoidance response. In contrast, activation of opioid receptors in the amygdala does not affect performance in a spontaneous alternation task. The pattern cmcrging suggests that the opioids, as well as other neurotransmitter systems, are involved in several types of memory or memories that are defined by the relevant neural system and task. Furthermore, intra-amygdala glucose injections attenuate the inhibitory avoidance deficit induced by intra-amygdala morphine injections. This finding indicates another brain region where glucose affects brain functions, possibly by direct inter- 
actions with the opioid system and/or other neurotransmitter systems, supporting the view that circulating glucose can modulate different brain systems.

\section{References}

Aggleton JP, Blindt HS, Rawlins JNP (1989) Effects of amygdaloid and amygdaloid-hippocampal lesions on object recognition and spatial working memory in rats. Behav Neurosci 103:962-974.

Bostock E, Gallagher M, King RA (1988) Effects of opioid microinjections into the medial septal area on spatial memory in rats. Behav Neurosci 102:643-652.

Brase DA, Han YH, Dewey WL (1987) Effects of glucose and diabetes on binding of naloxone and dihydromorphine to opiate receptors in mouse brain. Diabetes 36:1173-1177.

Brioni JD, Nagahara AH, McGaugh JL (1989) Involvement of the amygdala GABAergic system in the modulation of memory storage. Brain Res 487:105-112.

Cahill L, McGaugh JL (1990) Amygdaloid complex lesions differentially affect retention of tasks using appetitive and aversive reinforcement. Behav Neurosci 104:532-543.

Chrobak JJ, Stackman RW, Walsh TJ (1989) Intraseptal administration of muscimol produces dose-dependent memory impairments in the rat. Behav Neural Biol 52:357-369.

Decker MW, Radek RJ, Majchrzak MJ, Anderson DJ (1992) Differential effects of medial septal lesions on spatial-memory tasks. Psychobiology 20:9-17.

Dolezal V, Tucek S (1982) Effects of choline and glucose on atropineinduced alteration of acetylcholine synthesis and content in the brain of rats. Brain Res 240:285-293.

Dunn LT, Everitt BJ (1988) Double dissociations of the effects of amygdala and insular cortex lesions on conditioned taste aversion, passive avoidance, and neophobia in the rat using the excitotoxin ibotenic acid. Behav Neurosci 102:3-23.

Flood JF, Garland JS, Morley JE (1992) Evidence that cholecystokinin-enhanced retention is mediated by changes in opioid activity in the amygdala. Brain Res 585:94-104.

Frankhuijzen AL, Jansen FP, Schoffelmeer ANM, Mudler AH (1991) $\mu$-Opioid receptor-mediated inhibition of the release of radiolabelled noradrenaline and acetylcholine from rat amygdala slices. Neurochem Int 19:543-548.

Gallagher M, Kapp BS (1978) Manipulation of opiate activity in the amygdala alters memory processes. Life Sci 23:1973-1978.

Gibson GE, Blass JP (1976) Impaired synthesis of acetylcholine in brain accompanying mild hypoxia and hypoglycemia. J Neurochem $27: 37-42$.

Gibson GE, Peterson C (1981) Aging decreases oxidative metabolism and the release and synthesis of acetylcholine. J Neurochem 37:978984.

Givens BS, Olton DS (1990) Cholinergic and gabaergic modulation of medial septal area: effect on working memory. Behav Neurosci 104:849-855.

Gold PE (1986) Glucose modulation of memory storage processing. Behav Neural Biol 45:342-349.

Gold PE (1991) An integrated memory regulation system: from blood to brain. In: Peripheral signaling of the brain: neural-immune interactions, learning and memory (Frederickson RCA, McGaugh JL, Felten DL, eds), pp 391-420. Toronto: Hogrefe \& Huber.

Gold PE (1994) Modulation of emotional and non-emotional memories: same pharmacological systems, different neuroanatomical systems. In: Brain and memory: modulation and mediation of neuroplasticity (McGaugh JL, Weinberger NM, Lynch GS, eds), in press. New York: Oxford UP.

Gold PE, Hankins L, Edwards RM, Chester J, McGaugh JL (1975) Memory interference and facilitation with posttrial amygdala stimulation: effect on memory varies with footshock level. Brain Res 86: 509-513.

Gold PE, Rose RP, Hankins LL (1978) Retention impairment produced by unilateral amygdala stimulation: reduction by posttrial amygdala stimulation. Behav Biol 22:515-523.

Hall JL, Gonder-Frederick LA, Chewning WW, Silveira J, Gold PE (1989) Glucose enhancement of performance on memory tests in young and aged humans. Neuropsychologia 27:1129-1138.

Hitchcock JM, Davis M (1987) Fear-potentiated startle using an au- ditory conditioned stimulus: effect of lesions of the amygdala. Physiol Behav 39:403-408.

Ikonomidou-Turski C, Cavalheiro A, Turksi WA, Bortolotto 7.A, Turski $\mathrm{L}$ (1987) Convulsant action of morphine, [D-Ala ${ }^{2}$, D-Leu $\left.{ }^{5}\right]$-enkephalin and naloxone in the rat amygdala: electroencephalographic, morphological and behavioral sequelae. Neuroscience 20:671-686.

Introini-Collison IB, Nagahara A, McGaugh JL (1989) Memory enhancement with intra-amygdala post-training naloxone is blocked by concurrent administration of propranolol. Brain Res 476:94-101.

Izquierdo I, DaCunha C, Rosat R, Jerusalinsky D, Ferreira MBC, Medina JH (1992) Neurotransmitter receptors involved in post-training memory processing by the amygdala, medial septum, and hippocampus of the rat. Behav Neural Biol 58:16-26.

Kemble ED, Davis VA (1981) Effects of prior environmental enrichment and amygdaloid lesions on consummatory behavior, activity, predation and shuttle box avoidance in male and female rats. Physiol Psychol 9:340-346.

Kesner RP (1992) Learning and memory in rats with an emphasis on the role of the amygdala. In: The amygdala: neurobiological aspects of emotion, memory, and mental dysfunction (Aggleton JP, ed), pp 379-399. New York: Wiley-Liss.

Kesner RP, Andrus RG (1982) Amygdala stimulation disrupts the magnitude of reinforcement contribution to long-term memory. Physiol Psychol 10:55-59.

Kesner RP, Crutcher KA, Omana H (1990) Memory deficits following nucleus basalis magnocellularis lesions may be mediated through limbic, but not neocortical, targets. Neuroscience 38;93-102.

LeDoux JE (1992) Emotion and the amygdala. In: The amygdala: neurobiological aspects of emotion, memory, and mental dysfunction (Aggleton JP, ed), pp 339-352. New York: Wiley-Liss.

Lee MK, Graham SN, Gold PE (1988) Memory enhancement with posttraining intraventricular glucose injections in rats. Behav Neurosci 102:591-595.

Liang KC, McGaugh JL (1983) Lesions of the stria terminalis attenuate the enhancing effect of post-training epinephrine on retention of an inhibitory avoidance response. Behav Brain Res 9:49-58.

Manning CA, Hall JL, Gold PE (1990) Glucose effects on memory and other neuropsychological tests in elderly humans. Psychol Sci 1:307-311.

Manning CA, Parsons MW, Gold PE (1992) Anterograde and retrograde enhancement of 24 -hour memory by glucose in elderly humans. Behav Neural Biol 58:125-130.

Manning CA, Ragozzino ME, Gold PE (1993) Glucose enhancement of memory in patients with Alzheimer's disease. Neurobiol Aging 14: 523-528.

McDonald RJ, White NM (1993) A triple dissociation of the memory systems: hippocampus, amygdala and dorsal striatum. Behav Neurosci 107:3-22.

McGaugh JL, Introini-Collison IB, Nagahara AH (1988) Memoryenhancing effects of posttraining naloxone: involvement of $\beta$-noradrenergic influences in the amygdaloid complex. Brain Res 446:3749.

McGaugh JL, Introini-Collison IB, Cahill LF, Castellano C, Dalmaz C, Parent MB, Williams CL (1994) Neuromodulatory systems and memory storage: role of the amygdala. Behav Brain Res 58:81-90.

McGowan BK, Hankins W, Garcia J (1972) Limbic lesions and control of the internal and external environment. Behav Biol 7:841-852.

Means LW, Fernandez TJ (1992) Daily glucose injections facilitate performance of a win-stay water-escape working memory task in mice. Behav Neurosci 106:345-350.

Messier C, Destrade C (1988) Improvement of memory for an operant response by post-training glucose in mice. Behav Brain Res 31:185191.

Messier C, White NM (1987) Memory improvement by glucose, fructose, and two glucose analogs: a possible effect on peripheral glucose transport. Behav Neural Biol 48:104-127.

Messier C, Durkin T, Mrabet O, Destrade C (1990) Memory-improving actions of glucose: indirect synthesis evidence for a facilitation of hippocampal acetylcholine synthesis. Behav Brain Res 39: $135-143$.

Mesulam MM, Mufson EJ, Wainer BJ, Levey AI (1983) Central cholinergic pathways in the rat: an overview based on an alternative nomenclature (Ch1-Ch6). Neuroscience 10:1185-1201.

Mizumori SJY, Perez GM, Alvarado MC, Barnes CA, McNaughton BL 
(1990) Reversible inactivation of the medial septum differentially affects two forms of learning in rats. Brain Res 528:12-20.

Packard MG, White NM (1990) Effect of posttraining injections of glucose on acquisition of two appetitive learning tasks. Psychobiology 18:282-286.

Parsons MW, Gold PE (1992) Scopolamine-induced deficits in spontaneous alternation performance: attenuation with lateral ventricle injections of glucose. Behav Neural Biol 57:90-92.

Peinado-Manzano MA (1990) The role of the amygdala and the hippocampus in working memory for spatial and non-spatial information. Behav Brain Res 38:117-134.

Pellegrino LJ, Pellegrino AS, Cushman AJ (1979) A stereotaxic atlas of the rat brain. New York: Plenum.

Ragozzino ME, Gold PE (1991) Glucose effects on mecamylamineinduced memory deficits and decreases in locomotor activity in mice. Behav Neural Biol 56:271-282.

Ragozzino ME, Parker ME, Gold PE (1992) Spontaneous alternation and inhibitory avoidance impairments with morphine injections into the medial septum: attenuation by glucose administration. Brain Res 597:241-249.

Ragozzino ME, Arankowsky-Sandoval G, Gold PE (1994) Glucose attenuation of the effect of combined muscarinic-nicotinic blockade on spontaneous alternation. Eur J Pharmacol 256:31-36.

Ricny J, Tucek S, Novakova J (1992) Acetylcarnitine, carnitine and glucose diminish the effect of muscarinic antagonist quinuclidinyl benzilate on striatal acetylcholine content. Brain Res 576: 215-219.

Rodgers RJ (1978) Influence of intra-amygdaloid opiate injections on shock thresholds, tail-flick latencies and open field behavior in rats. Brain Res 153:211-216.

Sarter M, Bodewitz G, Stephens DN (1988) Attenuation of scopolamine-induced impairment of spontaneous alternation behavior by antagonist but not inverse antagonist and agonist $\beta$-carbolines. Psychopharmacology (Berlin) 94:491-495.

Shook JE, Kachur JF, Brase DA, Dewcy WL (1986) Morphine dcpendence and diabetes. II. Alterations of normorphine potency in the guinea-pig ileum and mouse vas deferens and of ileal morphine dependence by changes in glucose concentration. J Pharmacol Exp Ther 237:848-852.
Simon GS, Dewey WL (1981) Narcotics and diabetes. I. The effects of streptozotocin-induced diabetes on the antinociceptive potency of morphine. J Pharmacol Exp Ther 218:318-323.

Stackman RW, Walsh TJ (1992) Chlordiazepoxide-induced working memory impairments: site specificity and reversal by flumazenil (RO15-1788). Behav Neural Biol 57:233-243.

Stone WS, Cottrill KL, Gold PE (1987) Glucose and epinephrine attenuation of scopolamine-induced increases in locomotor activity in mice. Neurosci Res Commun 1:105-111.

Stone WS, Croul CE, Gold PE (1988a) Attenuation of scopolamineinduced amnesia in mice. Psychopharmacology (Berlin) 96:417-420.

Stone WS, Cottrill KL, Walker DL, Gold PE (1988b) Blood glucose and brain function: interactions with CNS cholinergic systems. Behav Neural Biol 50:325-334.

Stone WS, Rudd RJ, Gold PE (1990) Glucose and physostigmine effects on morphine- and amphetamine-induced increases in locomotor activity in mice. Behav Neural Biol 54:146-155.

Stone WS, Walser B, Gold SD, Gold PE (1991) Scopolamine- and morphine-induced impairments of spontaneous alternation performance in mice: reversal with glucose and with cholinergic and adrenergic agonists. Behav Neurosci 105:264-271.

Tucek S (1978) Acetylcholine synthesis in neurons. New York: Halsted.

Tucek S, Cheng SC (1974) Provenance of acetyl group of acetylcholine and compartmentalization of acetyl-CoA and Krebs cycle intermediates in the brain in vivo. J Neurochem 22:893-914.

Walker DL, McGlynn T, Grey C, Ragozzino M, Gold PE (1991) Naloxone modulates the behavioral effects of cholinergic agonists and antagonists. Psychopharmacology (Berlin) 105:57-62.

White NM (1991) Peripheral and central memory enhancing actions of glucose. In: Peripheral signaling of the brain: role in neural-immune interactions, learning and memory (Frederickson RCA, McGaugh JL, Felten DL, eds), pp 421-442. Toronto: Hogrefe \& Huber.

Winocur G, Mills JA (1969) Hippocampus and septum in response inhibition. J Comp Physiol Psychol 67:352-357.

Zamir N, Palkovits M, Brownstein M (1985) Distribution of immunoreactive met-enkephalin-Arg ${ }^{6}-\mathrm{Gly}^{7}-\mathrm{Leu}^{8}$ and leu-enkephalin in discrete regions of the rat brain. Brain Res 326:1-8. 